\title{
Turbulence parameter estimations from high-resolution balloon temperature measurements of the MUTSI-2000 campaign
}

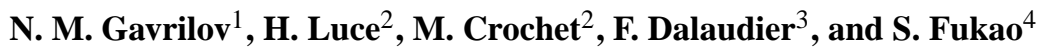 \\ ${ }^{1}$ Saint-Petersburg State University, Atmospheric Physics Department, Petrodvorets, 198504, Russia \\ ${ }^{2}$ Laboratoire de Sondages Electromagnétiques de l'Environnement Terrestre, Université de Toulon et du Var, France \\ ${ }^{3}$ Service d'Aéronomie du CNRS, BP3, 91371, Verrières le Buisson, Cedex, France \\ ${ }^{4}$ Research Institute for Sustainable Humanosphere, Kyoto University, Uji, 611-0011, Japan
}

Received: 25 February 2005 - Revised: 28 July 2005 - Accepted: 3 August 2005 - Published: 14 October 2005

\begin{abstract}
Turbulence parameters in the tropo-stratosphere are analyzed using high-resolution balloon temperature measurements collected during the MUTSI (MU radar, Temperature sheets and Interferometry) campaign which took place near the Middle and Upper atmosphere (MU) radar (Japan, $35^{\circ} \mathrm{N}, 136^{\circ} \mathrm{E}$ ) in May 2000 . Vertical profiles of the specific dissipation rate of turbulent kinetic energy, $\varepsilon$, and turbulent diffusivity, $K$, are estimated from the Thorpe lengthscale, $L_{T}$. The last is obtained by using two methods. The first one consists of measuring directly $L_{T}$ by reordering the potential temperature profiles. The second method is based on estimates of the temperature structure constant, $C_{T}^{2}$. A relationship between $L_{T}$ and $C_{T}^{2}$ can be found by assuming either adiabatic vertical displacements or a model based on turbulent energy balance consideration. Analysis shows that the adiabatic assumption gives indirect estimates of $L_{T}$ more consistent with direct measurements. We also found that vertical profiles of analyzed turbulence characteristics show substantial intermittency, leading to substantial scatter of the local, median and average values. General trends correspond to a decrease in $\varepsilon$ and $K$ from the boundary layer up to altitudes $20-25 \mathrm{~km}$. Layers of increased turbulence are systematically observed in the tropo-stratosphere, which may be produced by instabilities of temperature and wind profiles. These maxima may substantially increase local values of turbulence diffusivity.
\end{abstract}

Keywords. Meteorology and atmospheric dynamics (Turbulence)

\section{Introduction}

Atmospheric turbulence is an important subject in the atmospheric sciences. Accurate estimates of the dissipation of en- ergy by turbulence and increased heat conduction by turbulent diffusion are important for a full understanding of atmospheric energetic and dynamic processes. Turbulent mixing and diffusion of natural and anthropogenetic gas species control atmospheric composition below the turbopause (normally located above an altitude of $100 \mathrm{~km}$ ). For these reasons, effects of turbulence are now involved into practically all theoretical and numerical models of atmospheric circulation, dynamics, energetics and composition. The most essential turbulence parameters for such models are the specific rate of dissipation of kinetic energy, $\varepsilon$, and turbulent diffusivity, $K$. These turbulence parameters describe the efficiency of turbulent mixing at small scales. They need to be accurately quantified for estimating the turbulence effect on atmospheric chemistry, and in particular, on the vertical distribution of chemical species.

Estimates of $\varepsilon$ and $K$ in the atmosphere have been performed using different experimental techniques. Some insitu measurements of turbulence in the middle atmosphere made before 1990 are cited by Fukao et al. (1994). More recent studies were made using rockets (Roper, 1996; Khananian, 1996; Lübken, 1997, Lübken et al., 2002;), balloons (Hocking and $\mathrm{Mu}, 1997$; Luce et al., 2002) and aircrafts (Strunin and Shmeter, 1996; Pavelin et al., 2002; Cho et al., 2003). Systematic measurements of $\varepsilon$ and $K$ at different altitudes were made using MF, MST and UHF radars (e.g. Kurosaki et al., 1996; Naström and Eaton, 1997; Hall et al., 1998; Bertin et al., 1999; Dole and Wilson, 2001; Satheesan and Krishna Murthy, 2002; Kelly et al., 2003; Zink et al., 2004), and with acoustic (Agrovskii and Kukharets, 1998; Furumoto and Tsuda, 2001) and optical measurements (Kao et al., 2002; Hecht et al., 2004). Recently, extensive information about profiles of turbulence characteristics was obtained from optical observations of star scintillations from satellites (Gurvich et al., 2001). 
Despite a large amount of experimental data, there are substantial discrepancies between the estimates from the different methods and experiments. This may be explained by differences between experimental techniques used, and by the complex structure of nonlinear intermittent turbulence in the atmosphere (see reviews by Hocking, 1999 and Wilson, 2004). Therefore, the application of different methods for estimating turbulence parameters from the same data sets would give extra credence to the results if they are selfconsitent. In the present paper, we compare methods of estimations of $\varepsilon$ and $K$ from vertical profiles of (potential) temperature. To this end, we use the results of high resolution $(10 \mathrm{~cm})$ and high-accuracy $(2 \mathrm{mK})$ balloon temperature measurements in the tropo-stratosphere obtained during the MU Radar, Temperature Sheets and Interferometry (MUTSI) campaign performed in May 2000 in Shigaraki, Japan, $35^{\circ} \mathrm{N}$, $136^{\circ} \mathrm{E}$ (Luce et al., 2001).

Methods used for estimating $\varepsilon$ and $K$ are based on characteristic lengthscales of steady-state turbulence. Ozmidov (1965) defined a scale $L_{O}$ corresponding to the equilibrium between the inertia and buoyancy forces as follows: $L_{O}=\sqrt{\varepsilon / N^{3}}$, where $N$ the Brunt-Väisälä frequency. As a substitute for $L_{O}$, the Thorpe lengthscale $L_{T}$ was recently used in stably stratified fluids, such as lakes and ocean (e.g. Thorpe, 1977, Caldwell, 1983, Smyth and Moum, 2000). It quantifies the vertical overturns in density or potential temperature profiles. Some experimental and numerical studies have been performed to relate the Ozmidov scale $L_{O}$ to the Thorpe lengthscale $L_{T}$ (e.g. Smyth et al., 2001). Such a relationship would permit us to estimate $\varepsilon$ and $K$ from the sole potential temperature (or density) profile, as explained in Sect. 2.

We use two methods for estimating the Thorpe lengthscale $L_{T}$. The first method consists of measuring directly $L_{T}$, as already proposed by Caldwell (1983), Dillon and Park (1987) and Fer et al. (2004), for turbulent mixing in ocean. The second method consists of estimating $L_{T}$ indirectly from the temperature structure constant $C_{T}^{2}$ using two different models. The parameter $C_{T}^{2}$, can be estimated from balloon temperature measurements with horizontal pairs of distant sensors. The second method may be also useful for experiments, when $L_{T}$ cannot be measured directly, but $C_{T}^{2}$ and $N$ are available.

In Sect. 2, we describe the basics of the methods used for the comparisons. Section 3 is devoted to the practical aspects of analysis of MUTSI balloon data. Results of the analysis of vertical profiles of turbulence characteristics in the tropostratosphere are given in Sect. 4 and discussed in Sect. 5, in light of other methods and estimations of turbulence parameters found in the literature.

\section{Methods of turbulence parameter estimations}

As explained in Introduction, turbulent kinetic energy dissipation rate, $\varepsilon$, and turbulent diffusivity, $K$, are estimated from the Thorpe lengthscale $L_{T}$, which is related to the
Ozmidov lengthscale $L_{O}$. Indeed, it is usually found from in-situ experiments that $L_{O} / L_{T} \approx 1$ (in a statistical sense) in oceanic or lake data (e.g. Dillon, 1982; Moum, 1996; Ferron et al., 1998; Gargett, 1999). Dillon (1982) found $L_{T} \approx 1.25 L_{O}$ in the oceanic thermocline. Ferron et al. (1998) proposed $L_{T} \approx(0.95 \pm 0.6) L_{O}$ from equatorial oceanic data and Alisse (1999) found experimental $L_{T}=1.15 L_{O}$ for homogeneous stratospheric turbulent layers. These observations are in agreement with the "continuous creation" theory (e.g. Caldwell, 1983), according to which fluctuations of kinetic energy and temperature are permanently created on many scales: All the driving energy is converted into turbulent kinetic energy such that $L_{T}$ is proportional to $L_{O}$. Another theory proposed by Gibson (1982) and called the "big bang" theory supposes that "active" turbulence is a rare and localized event and that most of the observations would reveal remnant structures. Our measurements cannot distinguish between active and remnant turbulence. Most of our data are obtained for convectively stable temperature profiles, where remnant turbulence should be subject to a fast decay due to work of buoyancy forces.

In our consideration we use only formulae for a dry atmosphere, because high resolution measurements of humidity are not available. They are good approximations for the upper troposphere and stratosphere, where humidity is weak. But the reader must keep in mind that only the contribution of the dry atmospheric component is considered for the troposphere data shown below.

\subsection{Direct measurements of $L_{T}$}

For steady-state turbulence, energy dissipation rate, $\varepsilon$, and turbulent diffusivity, $K$, are related to the Ozmidov scale by:

$\varepsilon \approx L_{O}^{2} N^{3}$

$K \approx \beta L_{O}^{2} N$,

where $\beta$ is a constant, and local values of $N$ are determined for the same layer altitudes. According to a review by Fukao et. al. (1994), $\beta$ may vary between 0.2 and 1 . The frequently used approximation $\beta=R_{f} /\left(1-R_{f}\right)$, where $R_{f}$ is the flux Richardson number, often taken as $R_{f} \approx 0.25$, gives $\beta \approx 1 / 3$. Assuming $L_{O}=c L_{T}$, estimations of $\varepsilon$ and $K$ can be made from the following formulae proposed by Caldwell (1983) and more recently by Galbraith and Kelley (1996) and Fer et al. ( 2004):

$$
\begin{aligned}
& \varepsilon \approx\left(c L_{T}\right)^{2} N^{3} \\
& K \approx \beta\left(c L_{T}\right)^{2} N .
\end{aligned}
$$

For adiabatic random vertical motions of fluid particles, the Thorpe length $L_{T}$ can be obtained from high resolution balloon potential temperature measurements by calculating the standard deviation of displacements $l^{\prime}$ obtained from re-ordering potential temperature profiles (e.g. Luce et al., 2002). Considering the result given by Alisse (1999) for stratospheric data, $c=1.15$ will be used. One should keep 
in mind that this value has been obtained from selected "statistically homogeneous turbulence layers" and may thus be different in other situations.

From numerical simulations of turbulent flows, Smyth and Moum (2000) found that the ratio $L_{O} / L_{T}$ could increase with time for turbulence generated by shear instability: it may be significantly smaller than 1 at the beginning stage of mixing and larger than 1 for the mature (when turbulence already decays). They used the ratio $L_{O} / L_{T}$ for estimating the age of a KHI-generated turbulent layer. Therefore, estimates Eqs. (3) and (4) may contain errors in regions where turbulence is not in a developed stage. In particular, $L_{O} \gg L_{T}$ may be expected in nearly mixed layers because they may correspond to a mature stage of turbulence, which is not usually considered in the "continuous creation" theory. Also, $L_{T}$ estimates may be not reliable in layers with small $N^{2}$, due to the contribution of instrumental noise (Galbraith and Kelley, 1996). These two limitations have to be taken into account when interpreting the experimental results in regions of weak stability, which are more frequent in the troposphere.

\subsection{Indirect estimates of $L_{T}$ from $C_{T}^{2}$}

A first approach is based on the above-mentioned model of adiabatic vertical displacements corresponding to fluctuations of potential temperature $\theta^{\prime}$. These vertical displacements are assumed to be small enough so that:

$\theta^{\prime}=-l^{\prime} d \theta_{0} / d z$

where $l^{\prime}$ denotes the vertical displacement and $\theta_{0}(z)$ denotes the vertical background (non perturbated) potential temperature profile. Since the Brunt-Väissälä frequency $N$ is defined as:

$N^{2}=\frac{g}{\theta_{0}} \frac{d \theta_{0}}{d z}$,

one can modify Eq. (6) as follows:

$\frac{\theta^{\prime}}{\theta_{0}}=-l^{\prime} \frac{N^{2}}{g}$.

Taking the variance of the random variables $\theta^{\prime}$ and $l^{\prime}$, it follows that:

$\frac{\overline{\theta^{\prime 2}}}{\theta_{0}^{2}}=L_{T}^{2} \frac{N^{4}}{g^{2}}$

where $L_{T}^{2}=\overline{l^{\prime 2}}$ is the so-called Thorpe lengthscale. From Eq. (8), we obtain:

$L_{T} \simeq \frac{g \sqrt{T^{\prime 2}}}{N^{2} T_{0}}$

by using $\overline{\theta^{\prime 2}} / \theta_{0}^{2} \approx \overline{T^{\prime 2}} / T_{0}^{2}$ (see Tatarskii, 1971). The temperature variance involved in Eq. (9) can be related to the temperature structure function (Tatarskii, 1971). Balloon measurements from the MUTSI campaign provided vertical profiles of temperature with pairs of sensors horizontally separated by $r=1 \mathrm{~m}$. An estimate of the structure function can be obtained assuming a homogeneous and isotropic temperature field:

$D_{T}(r)=\overline{[T(x+r)-T(x)]^{2}}=2 \overline{T^{\prime 2}}[1-R(r)]$,

where the averaging is performed over an altitude layer and $R(r)$ is the cross-correlation function defined as:

$R(r)=\overline{T^{\prime}(x+r) T^{\prime}(x)} / \overline{T^{\prime 2}}$.

It follows from Eq. (10):

$\overline{T^{\prime 2}}=D_{T}(r) /[2(1-R(r))]$.

It can be noted that if $R(r) \rightarrow 0$, then $\overline{T^{\prime 2}}=D(r) / 2$. In the inertial subrange of isotropic and homogeneous turbulence $D_{T}(r)=C_{T}^{2} r^{2 / 3}$, then Eq. (9) can be expressed in terms of $C_{T}^{2}$ :

$L_{T}^{r}=\frac{\left[0.5 \alpha(r) C_{T}^{2} g^{2} T_{0}^{-2}\right]^{1 / 2}}{N^{2}}, \quad \alpha(r)=\frac{r^{2 / 3}}{1-R(r)}$,

where the function $\alpha(\mathrm{r})$ is introduced for simplifying the formula.

\subsection{Remarks about the proposed methods}

Expression (13) is only justified for the inertial subrange of homogeneous and isotropic turbulence which can be described by correlation functions (and variances). A slightly more general expression could be obtained for non-inertial turbulence by combining Eqs. (9) and (12), i.e. by expressing $L_{T}^{r}$ as a function of $D_{T}(r)$. Using Eq. (13), the Thorpe lengthscale $L_{T}$ (and thus in some way $L_{o}$ ) can be estimated from $C_{T}^{2}, N^{2}, T_{0}$ and $R(r)$. The most difficult point concerns $R(r)$ which cannot be estimated without high-resolution temperature measurements. For $r$ larger than the outer scale of turbulence, one may suppose $R(r) \rightarrow 0$. For $r=1 \mathrm{~m}$ this approximation is not valid for many cases and in this study we estimate $R(r)$ from MUTSI balloon high-resolution temperature measurements (see Sect. 4).

Another model is available in the literature for estimating $\epsilon$ from (potential) temperature data (e.g. Ottersten, 1969; Weinstock, 1981; Bertin et al., 1997). It is based on the consideration of turbulence energy balance (see Ottersten, 1969) with the hypothesis of incompressibility, isotropic and stationary turbulence. In our notations and in the absence of humidity, this approach is equivalent to the following formula:

$\varepsilon_{e} \approx\left[\frac{\left(1-R_{f}\right)}{R_{f}} \frac{C_{T}^{2} g^{2}}{a^{2} T_{0}^{2} N^{2}}\right]^{3 / 2}$,

where $a^{2} \approx 2.8$ is a universal constant. Hocking and $\mathrm{Mu}$ (1997) gave a more in-depth discussion of this formula, and also included different variations of it from other authors. After Lilly et al. (1974), one may assume $R_{f}=0.25$, even though it is believed to be smaller in regions of turbulence 
production. Using Eq. (3), one can obtain from Eq. (14) the following expression for the Thorpe length:

$L_{T}^{e} \approx \frac{\left[0.88 C_{T}^{2} g^{2} T_{0}^{-2}\right]^{3 / 4}}{N^{3}}$.

Expression (15) has a general structure similar to Eq. (13), since it depends on the same parameters $C_{T}^{2}, N^{2}$ and $T_{0}$. However, Eq. (15), contains higher powers of $C_{T}$ and $N$ in the denominator compared to Eq. (13). Comparison of estimations of $L_{T}^{r}$ and $L_{T}^{e}$ using Eqs. (13) and (15) with directly measured Thorpe lengthscale $L_{T}$ (see Sect. 2.1), are given in Sects. 4 and 5.

It is worth noting that Eq. (4) gives estimates of local turbulent diffusivity at small scales only. At larger scales, turbulence intermittency is important (see discussion in Sect. 5); also additional mechanisms of diffusion, such as stokes diffusion, may exist (see review by Hocking, 1999).

\section{Processing MUTSI balloon data}

The methods of estimating turbulence characteristics described in the previous section were applied to the available high-resolution temperature profiles. Ten instrumented balloons labeled here as M1,..., M10 for these temperature measurements were launched near the MU radar. We used temperature (and pressure) profiles obtained during balloon flights M1, M8 and M9 launched on 13 May, 22/23 May and 25/26 May 2000, respectively. The detailed description of the instrumentation was made by Luce et al. $(2001,2002)$.

\subsection{Direct measurements of Thorpe lengths}

First, vertical potential temperature profiles at a vertical resolution of $\Delta z=10 \mathrm{~cm}$ are calculated from profiles of temperature and pressure. Thorpe-reordered profiles are then obtained and fluid particle displacements needed for that reordering are calculated, as described by Luce et al. (2002). Thorpe lengthscales are finally deduced as standard deviations of these displacements for data within vertical segments, with thickness $\delta z=12.8 \mathrm{~m}$ shifting with a step of $6.4 \mathrm{~m}$. A small segment thickness of $12.8 \mathrm{~m}$ is chosen for obtaining sufficiently high vertical resolution while keeping a sufficient number of data points in each segment. Inspection of the Thorpe displacement profiles reveals that this value of $\delta z$ generally corresponds to typical thicknesses of stratospheric turbulent layers, where overturning of fluid particles occur. In case of thick turbulent layers, when the Thorpe length is much larger than $\delta z$, the calculation of turbulent characteristics for thin segments may produce increased variability within the layers and especially near their edges. Our verification shows that increase in the thickness of data segments $\delta z$ does not affect qualitatively the results and thus our conclusions, but gives lower vertical resolution in the stratosphere, where turbulence is highly intermittent.

Estimating $N^{2}$ is made after Galbraith and Kelley (1996) from the reordered potential temperature profile (see above).
For each 12.8-m thick vertical segment, a linear fitting is applied to the reordered $\theta$ profile. The slope of the linear curve used for $\partial \theta_{0} / \partial z$ and $N^{2}$ is estimated by calculating from Eq. (6) with $\theta_{0}$ in the denominator, taken as the mean value of $\theta$ in the selected segment.

Estimating $\mathrm{C}_{T}^{2}$ is made for each vertical segment of thickness $\delta z$. The structure function $D_{T}(r)$ for $r=1 \mathrm{~m}$ is estimated by calculating the variance of the differences in temperature, measured by two horizontal sensors separated by a distance of $1 \mathrm{~m}$. The temperature differences with vertical step of $0.1 \mathrm{~m}$ are first calculated and then their mean value over the segment is calculated and subtracted in order to suppress possible absolute decalibration between the sensors. This decalibration may slowly vary with height, but inspection of the temperature profiles shows that it is usually quite constant within segments with $\delta z=12.8 \mathrm{~m}$. The numerical value of $D_{T}(r)$ at $r=1 \mathrm{~m}$ is equal to the numerical value of $C_{T}^{2}$, provided that the scale $1 \mathrm{~m}$ belongs to the inertial subrange of the Kolmogorov turbulence. Use of a data segment of thickness $\delta z$ is equivalent to a numerical filter suppressing scales larger than $\delta z=12.8 \mathrm{~m}$. This can slightly underestimate $C_{T}^{2}$ but should not significantly affect our analysis (see Luce et al., 1997 for a discussion in a similar context).

\subsection{Estimating $R(r)$}

The reordered $\theta$ profiles are first converted into reordered $\mathrm{T}$ profiles using measured pressure profiles. The temperature differences $T_{1}^{\prime}(z)$ and $T_{2}^{\prime}(z)$ between the original and reordered temperature profiles are then calculated for the two horizontal distant sensors 1 and 2. The cross-correlation $R=\overline{T_{1}^{\prime} T_{2}^{\prime}} / \sqrt{\overline{T_{1}^{\prime 2} T_{2}^{\prime 2}}}$ is finally estimated for each altitude segment with thickness $\delta z=12.8 \mathrm{~m}$.

\subsection{Rejecting noise contribution}

Measured temperature and pressure data may contain random instrumental noise, which is normally assumed to be white and then noncorrelated for all sensors. In this case, the measured temperature may be represented as $T_{o b s}=T+n$, where $n$ is the noncorrelated noise. The observed temperature structure function for a separation $\xi$ may be represented as follows (see Gavrilov et al., 1994):

$D_{\text {Tobs }}(\xi)=D_{T}(\xi)+2 \sigma_{n}^{2}$,

where $\sigma_{n}^{2}$ is the noise variance. For atmospheric temperature it is supposed that $D_{T}(\xi) \rightarrow 0$ at $\xi \rightarrow 0$. Therefore, one may suppose that

$D_{\text {Tobs }}(\xi) \approx 2 \sigma_{n}^{2}$ at small $\xi$.

Balloon measurements have data sampling with vertical step $\Delta z=10 \mathrm{~cm}$. Using estimates of the vertical structure function $D_{\text {Tobs }}(\Delta z)$, one may obtain the simplest estimation

$\sigma_{n}^{2} \approx D_{\text {Tobs }}(\Delta z) / 2$.

However, in this case the estimate of $\sigma_{n}^{2}$ may contain not only contributions from the uncorrelated noise but also possibly 
Table 1. Noise standard deviations and numbers of selected data points according to different criteria for flights M1, M8 and M9.

\begin{tabular}{|c|c|c|c|c|c|c|}
\hline \multirow{2}{*}{ Parameter } & \multicolumn{3}{|l|}{ Troposphere } & \multicolumn{3}{|l|}{ Stratosphere } \\
\hline & M1 & M8 & M9 & M1 & M8 & M9 \\
\hline$\sigma_{n}, \mathrm{mK}$ & 2.1 & 2.4 & 2.4 & 2.2 & 2.2 & 2.3 \\
\hline $\mathrm{N}_{t o t}$ & 1792 & 1787 & 2152 & 2238 & 2434 & 1968 \\
\hline $\mathrm{N}\left(\mathrm{C}_{1}\right), \mathrm{C}_{1} \equiv D_{\text {Tobs }}(r)>4 \sigma_{n}^{2}$ & $976(54 \%)$ & $826(45 \%)$ & $1121(52 \%)$ & $1263(56 \%)$ & $1406(58 \%)$ & $1011(51 \%)$ \\
\hline $\mathrm{N}\left(\mathrm{C}_{2}\right), \mathrm{C}_{2} \equiv L_{T} d \theta_{0} / d z>2 \sigma_{n}$ & $1256(70 \%)$ & $1284(72 \%)$ & $1577(73 \%)$ & $2188(98 \%)$ & $2319(95 \%)$ & $1946(99 \%)$ \\
\hline $\mathrm{N}\left(\mathrm{C}_{1} \cap \mathrm{C}_{2}\right)$ & $883(49 \%)$ & $762(43 \%)$ & $1059(49 \%)$ & $1251(55 \%)$ & $1403(57 \%)$ & $1009(51 \%)$ \\
\hline
\end{tabular}

some variance due to the turbulence at scales less than $\Delta z$. Therefore, Eq. (18) may be not valid in regions of strong turbulence, and peaks of $D_{T o b s}(\Delta z)$ are indeed found in regions of large temperature fluctuations. Therefore, in our analysis, we estimate for each profile the mean values of $\sigma_{n}$, calculating after the exclusion of values exceeding $3 \mathrm{mK}$, which we suppose to have a substantial contribution of geophysical signal, in accordance with the inspections of measured vertical profiles of $D_{T o b s}(\Delta z)$. After calculating $\sigma_{n}$ from Eq. (18), the elimination of noise contribution is applied by the correction of the observed structure function Eq. (10) as follows:

$D_{T}(r)=D_{T o b s}(r)-2 \sigma_{n}^{2}$.

Also, all data for which $D_{T o b s}(r)<4 \sigma_{n}^{2}\left(\right.$ or $\left.D_{T}(r)<2 \sigma_{n}^{2}\right)$ are rejected from the analysis, since they may be strongly affected by instrumental noise. Similarly, all direct estimates of $L_{T}$ for which $L_{T} \partial \theta_{0} / \partial z<2 \sigma_{n}$ are rejected, since the Thorpe lengths can be strongly affected by instrumental noise for this condition, as it was shown using a numerical simulation by Alisse (1999). Both conditions are used below when comparing the directly estimated and reconstructed turbulence parameters.

\subsection{Estimating $L_{T}^{r}, \varepsilon$ and $K$}

Reconstructed $L_{T}^{r}$ values are estimated using Eq. (13) with values of $N^{2}, C_{T}^{2}$ and $R(r)$ given by the methods described above. The turbulent parameters $\varepsilon$ and $K$ are then estimated from Eqs. (3) and (4), using the directly measured Thorpe length $L_{T}$. Also, values $\varepsilon_{r}$ and $K_{r}$ are calculated from Eqs. (3) and (4) from $L_{T}^{r}$ reconstructed with Eq. (13). The value $\beta=1 / 3$ is used for estimating $K$ in Eq. (4). For comparison, we also calculated values $\varepsilon_{e}$ and $K_{e}$ with Eqs. (3) and (4), using $L_{T}^{e}$ given by Eq. (15).

\section{Results of the analysis}

\subsection{Elimination of data affected by noise}

Average standard deviations of noise fluctuations $\sigma_{n}$, determined from Eq. (18) for MUTSI flights M1, M8 and M9, are shown in Table 1 for the troposphere and stratosphere. The values differ only slightly between the flights. Also given in Table 1 are the total numbers of registered data segments $(12.8 \mathrm{~m})$ for the stratosphere and troposphere, for each flight, and the numbers of data for which the conditions $C_{1} \equiv D_{T o b s}(\mathrm{r})>4 \sigma_{n}^{2}$ at $r=1 \mathrm{~m}$ and/or $C_{2} \equiv L_{T}\left(\partial \theta_{0} / \partial \mathrm{z}\right)>2 \sigma_{n}$ are fulfilled. When the conditions are valid, we assume that estimates of turbulence parameters are more reliable (i.e. less affected by the noise - see Sect. 3). One can see from Table 1 that the proportions of reliable values of $C_{T}^{2}$ and $L_{T}$ are smaller in the troposphere than in the stratosphere, because the layers with small $\partial \theta_{0} / \partial \mathrm{z}$ and $C_{T}^{2}$ are more frequent in the troposphere.

Table 1 shows that our requirement $C_{1}$ removes more data points than the requirement $C_{2}$. But analysis shows that these conditions do not necessarily break down in the same altitude segments. Therefore, determination of turbulent parameters using temperature variances may give more reliable results in the regions where $\partial \theta_{0} / \partial z \rightarrow 0$, where the condition $C_{2}$ is not fulfilled, but the condition $C_{1}$ may still be valid. According to Table 1, such cases are more frequent in the troposphere. Also, estimations of turbulent parameters from temperature variances using Eqs. (3), (4) and (9) may be useful for experiments having smaller resolution in altitude, when direct measurements of the Thorpe length are not possible.

\subsection{Cross-correlation}

Expression (13) for $L_{T}^{r}$ involves the determination of the cross-correlation $R(r)$ of temperature fluctuations. Experimental study of this parameter from balloon measurements has never been performed previously. Values of $R(r)$ for a pair of temperature sensors located at horizontal distances $r=1 \mathrm{~m}$ are calculated as described in Sect. 3. Figure 1 represents the measured dependence of $R(r)$ on $L_{T}$ for data collected during the flight M1. All data affected by noise have been rejected, using both criteria $C_{1}$ and $C_{2}$ described above. Thus, the tendencies revealed by Fig. 1 are supposed to be relevant to geophysical processes. Figure 1 shows that $R(r)$ increases with $L_{T}$. Black squares indicate median values of $R(r)$ for different intervals of $L_{T}$ values. They can be approximated by a semi-empirical function. A large number of analytical functions can fit the experimental values of 


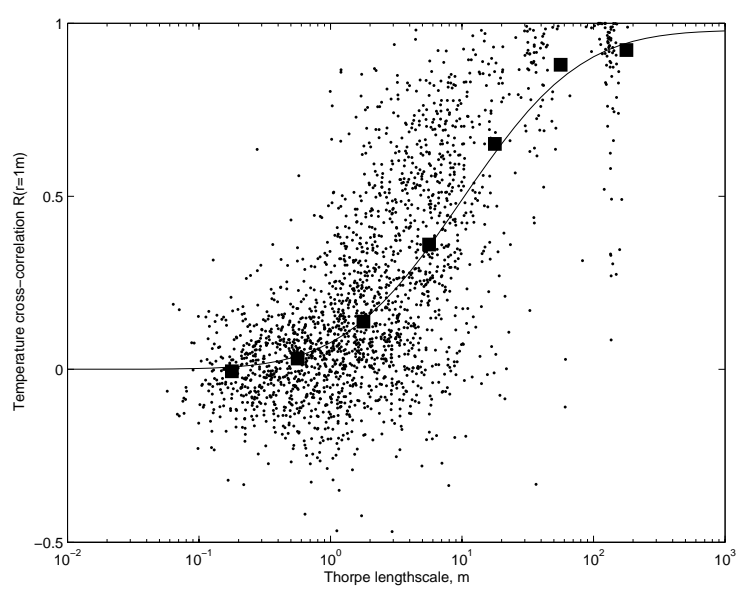

Fig. 1. Dependence of cross-correlation of temperature fluctuations for a pair of sensors horizontally separated with distance $r=1 \mathrm{~m}$ on measured Thorpe length in different altitude segments during flight M1. Solid line shows the approximation with Eq. (20) at $a=0.49$ and $L_{c}=10 \mathrm{~m}$, and thick black squares are median values of $R(r)$ in different bands of $L_{T}$ values.
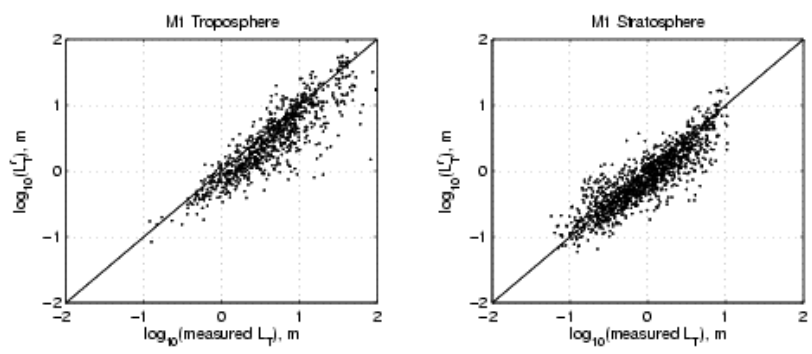

Fig. 2. Comparisons of directly measured and estimated Eq. (13) Thorpe lengthscales for the troposphere, below $11.5 \mathrm{~km}$ (left), and the stratosphere, above $11.5 \mathrm{~km}$ (right), during flight M1.

Fig. 1. For example, a possible compact formula may have the following form:

$R_{r=1 m}\left(L_{T}\right)=a\left[\operatorname{erf}\left(\log _{10}\left(L_{T} / L_{c}\right)\right)+1\right]$,

where $\operatorname{erf}(\mathrm{x})$ is the error function, $a$ and $L_{c}$ are constants. The solid curve in Figure 1 corresponds to relation (20) with values of $L_{c}=10 \mathrm{~m}$ and $a=0.49$. Empirical formulas, such as Eq. (20) may be useful for estimating $R(r)$ when there is no possibility for its experimental determination. Dependencies similar to Fig. 1 are obtained with a good approximation by Eq. (20) for all analyzed MUTSI balloon flights.

The increase in cross-correlation with $L_{T}$ revealed by Fig. 1 may be explained by changes in scales of turbulent eddies. For isotropic turbulence, vertical and horizontal scales of turbulence should be equal. Therefore, when the vertical Thorpe lengthscale is smaller than $r=1 \mathrm{~m}$, the horizontally spaced sensors may be generally influenced by different small-scale isotropic eddies and the correlation between them is small. When the Thorpe length increases, the proportion of larger-scale eddies also increases and the correlation between temperature fluctuations at two distant sensors in- creases. The contribution of anisotropic turbulence, having horizontal scales larger than vertical, may increase the correlation between two horizontally distant sensors, even for small Thorpe lengths, which may explain points with relatively large cross-correlation at small $L_{T}$ in Fig. 1.

\subsection{Turbulence parameters}

Figure 2 shows scatter plots of "indirect" Thorpe length $L_{T}^{r}$, estimated using Eq. (13), versus directly measured values $L_{T}$ for tropospheric and stratospheric data from the MUTSI flight M1. Similar tendencies have been obtained for data from flights M8 and M9. Also, similar plots (not shown) have been obtained for the turbulence parameters $\varepsilon$ and $\mathrm{K}$ obtained from Eqs. (3) and (4), respectively.

First, one can see that both distributions of $L_{T}$ and $L_{T}^{r}$ in Fig. 2 extend over several decades, revealing a strong vertical variability and intermittency of turbulence in the tropostratosphere. The comparison of $L_{T}$ and $L_{T}^{r}$ shows that values are located near the diagonal, corresponding to $L_{T}=L_{T}^{r}$, and the agreement is even slightly better for stratospheric data (means and standard deviations of the ratio $L_{T} / L_{T}^{r}$ are 1.90 and 2.53, respectively, for the tropopsheric data and 1.39 and 0.91 for the stratospheric data). This supports the possibility of estimating indirectly the Thorpe lengthscale using Eq. (13). In the troposphere, the directly measured $L_{T}$ values are often significantly larger than the indirect $L_{T}^{r}$ values. One assumption may be a possible overestimation of the Thorpe length directly measured in the layers of small $\partial \theta_{0} / \partial z$ due to the influence of noise. Also, small $N^{2}$ generally corresponds to small $C_{T}^{2}$ values, which can become only slightly larger than the noise level, and $L_{T}^{r}$ could be underestimated after the noise correction used in our study and described in Sect. 3.

Average and median values of the direct and indirect $L_{T}, \varepsilon$ and $K$ parameters for the three MUTSI flights are given in Table 2, even though the $K$ values may not represent the effective turbulent mixing in intermittent patches (see Sect. 2.3).

The median values in Table 2 for all turbulence parameters are substantially smaller than the mean values. This means that small individual values of turbulence parameters are more frequent than large values. This is a known feature of turbulence (Kolmogorov, 1962). On the other hand, relatively rare cases of strong turbulence may give a substantial contribution into energetic balance and diffusion processes in the atmosphere, which may be reflected by the mean values of the turbulence parameters.

Figures 3 and 4 show examples of vertical profiles of $L_{T}$ and $L_{T}^{r}$, respectively, in the troposphere and stratosphere. In these plots, no rejection criterion is applied, but the profiles are smoothed using a 3-point running window, in order to emphasize the main tendencies. The temperature, $C_{T}^{2}$ and $N^{2}$ profiles corresponding to the selected altitude ranges, are also given for interpreting the results. First, one can note an agreement between the positions of $L_{T}$ and $L_{T}^{r}$ maxima in both Figs. 3 and 4. This result gives extra credence to the 
proposed models of turbulence parameter estimation. Second, the agreement in the magnitudes of $L_{T}$ and $L_{T}^{r}$ is better in the stratosphere (Fig. 4) than in the troposphere (Fig. 3), where $L_{T}$ is generally larger than $L_{T}^{r}$, as expected from Fig. 2. Comparing the profiles shown in Figs. 3 and 4 shows that in some regions of large $N^{2}$, associated with maxima of $C_{T}^{2}$, the magnitudes of $L_{T}$ and $L_{T}^{r}$ agree well.

At altitudes around 17.1, 17.6, 17.9, and $18.25 \mathrm{~km}$ in Fig. 4, one can see increased temperature fluctuations even visible in the temperature profile. In contrast, in regions of small $N^{2}$ (i.e. nearly adiabatic gradient), which are more frequent in the troposphere (Fig. 3), the maxima of measured $L_{T}$ usually corresponds to small values of $C_{T}^{2}$ and smaller values of $L_{T}^{r}$.

This case is also seen around altitudes 17.2 and $18.5 \mathrm{~km}$ in Fig. 4. One reason for larger measured $L_{T}$ magnitudes in the layers of small $N^{2}$ may be their overestimation due to noise effects. Also, despite small $N^{2}, L_{T}^{r}$ may be smaller than $L_{T}$ because usually $C_{T}^{2}$ is also small. Therefore, $L_{T}^{r}$ may contain uncertainties because $\left(C_{T}^{2}\right)^{1 / 2} / N^{2}$ may become a poorly defined ratio of small values. One has to keep in mind that $L_{T}^{r}$ may be smaller than $L_{T}$ in Figs. 3 and 4 because the standard deviation of noise was subtracted from the observed $D_{\text {Tobs }}(r)$ (see Eq. (19)) when estimating $C_{T}^{2}$, while the measured $L_{T}$ values were not corrected for noise contribution.

Vertical profiles of turbulence parameters $\left(L_{T}, \varepsilon, K\right)$, wind speed and direction, and the squared Brünt-Vaïsala frequency $N^{2}$ (calculated using the method explained in Sect. 3) are shown for the flights M1, M8 and M9 in Figs. 5, 6 and 7 , respectively. The profiles of turbulence parameters contain only reliable estimates that were selected using criteria $C_{1}$ and $C_{2}$ (see Table 1 ), and both the directly measured and indirect values are plotted in green and red dots, respectively, because they may complement each other in numerous layers, where only one of the estimates is reliable, according to the criteria of Sect. 3. One can see general decreasing trends of these parameters from the boundary layer up to the altitudes of $20-25 \mathrm{~km}$ in Figs. 5-7. A striking fact is the strong inhomogeneity of the profiles, indicating that turbulence is most of the time confined within thin localized patches. However, regions favorable to stronger turbulence may superimpose on the decreasing trends, as indicated by increased values of $L_{T}, \varepsilon$ and $K$. Such regions can be found for flight M9 between altitudes 10-12 km, where clear maxima of $\left(L_{T}, \varepsilon, K\right)$ are observed, associated with a maximum of $N^{2}$ and $C_{T}^{2}$. A less pronounced, but a significant maximum for flight M9 can be noted around $18.5 \mathrm{~km}$, associated with a minimum of $N^{2}$. For flight M8, the largest local maxima of $\left(L_{T}, \varepsilon, K\right)$ can be found at altitudes 7-8 (associated with minima of $\mathrm{N}^{2}$ ) and $18-20 \mathrm{~km}$ (associated with maxima of $N^{2}$ and $C_{T}^{2}$ ). For flight M1, one may find local maxima of $\left(L_{T}, \varepsilon, K\right)$ within altitudes $10-12$ and 14-16 km, (associated with maxima of $N^{2}$ and $C_{T}^{2}$ ), for example. These maxima may substantially increase local median and mean values of turbulence characteristics.

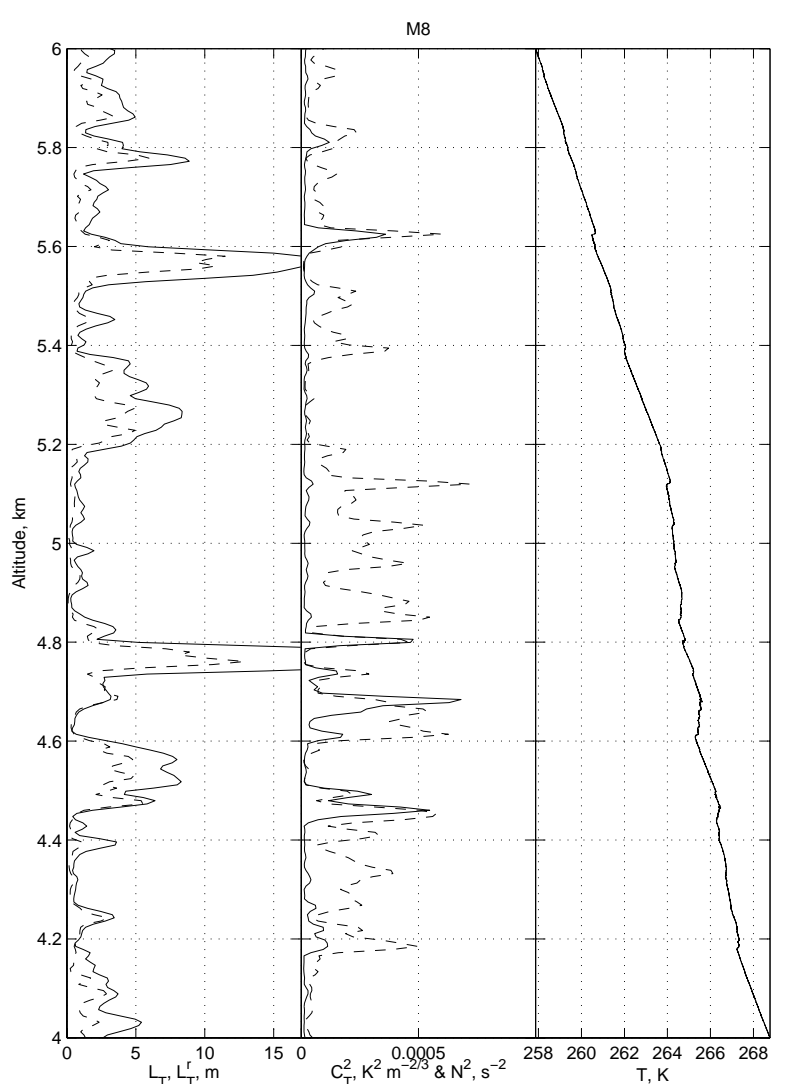

Fig. 3. Examples of (left) directly measured (solid line) and indirect (dashed line) Thorpe length and corresponding values (center) of $C_{T}^{2}$ (solid line) and $N^{2}$ (dashed line) and temperature (right) for flight M8 in the troposphere.

Wind speed and direction for flights M1 and M9 were obtained by Luce et al. (2001) from balloon measurements averaged for obtaining the same height resolution as the MU radar. For flight M8, balloon wind data are not available. The wind profiles shown in Fig. 6 have been obtained from MU radar observations at a radial resolution of $150 \mathrm{~m}$ averaged over $20 \mathrm{~min}$, corresponding to the time when the balloon altitude was between 18 and $20 \mathrm{~km}$.

Analysis of the wind profiles reveals that the layers of enhanced turbulence parameters sometimes correspond to regions of large variations of wind speed and/or direction, which may create shear instabilities in the atmosphere if the local Richardson number is small enough. For example, the well-defined maxima of $L_{T}, \varepsilon, K$ and $C_{T}^{2}$ in M9 data around $11-12 \mathrm{~km}$ seems to correspond to a large increase in wind speed as a function of height. Zones of shear instabilities may be more frequent in the lower and upper parts of the tropo-stratospheric jet stream. They may create layers of increased turbulence in the tropopause region. For flight M8, around $18-20 \mathrm{~km}$, the well-defined maximum seems to be related to changes in both wind speed and direction (even though they are not found exactly at the same altitude) and then to a possible strong shear. A more thorough analysis of 
Table 2. Median and average turbulence parameters for flights M1, M8 and M9.

\begin{tabular}{lllllll}
\hline Parameter & Troposphere & & & Stratosphere & & \\
& M1 & M8 & M9 & M1 & M8 & M9 \\
\hline$L_{\text {Tmed }}^{m} \& L_{\text {Tmean }}^{m}, \mathrm{~m}$ & $5.4 \& 19.3$ & $3.9 \& 9.3$ & $5.4 \& 24.6$ & $1.0 \& 1.6$ & $1.0 \& 1.7$ & $0.6 \& 1.1$ \\
$L_{\text {Tmed }}^{r} \& L_{\text {Tmean }}^{r}, \mathrm{~m}$ & $3.6 \& 18.3$ & $2.8 \& 7.7$ & $3.4 \& 24.3$ & $0.8 \& 1.5$ & $0.8 \& 1.6$ & $0.6 \& 1.0$ \\
$\varepsilon_{\text {med }} \& \varepsilon_{\text {mean }}, 10^{-5} \mathrm{~m}^{2} \mathrm{~s}^{-3}$ & $2.2 \& 110$ & $1.5 \& 18$ & $3.3 \& 360$ & $0.6 \& 3.0$ & $0.7 \& 4.7$ & $0.4 \& 1.7$ \\
$\varepsilon_{\text {rmed }} \& \varepsilon_{\text {rmean }}, 10^{-5} \mathrm{~m}^{2} \mathrm{~s}^{-3}$ & $1.2 \& 80$ & $0.8 \& 9$ & $1.5 \& 210$ & $0.5 \& 1.7$ & $0.5 \& 3.2$ & $0.4 \& 1.1$ \\
$K_{\text {med }} \& K_{\text {mean }}, \mathrm{m}^{2} \mathrm{~s}^{-1}$ & $0.1 \& 3.8$ & $0.5 \& 0.56$ & $0.11 \& 8.1$ & $0.007 \& 0.027$ & $0.0067 \& 0.033$ & $0.0033 \& 0.013$ \\
$K_{\text {rmed }} \& K_{\text {rmean }} \mathrm{m}^{2} \mathrm{~s}^{-1}$ & $0.047 \& 6.07$ & $0.027 \& 0.47$ & $0.043 \& 12.5$ & $0.0033 \& 0.02$ & $0.0033 \& 0.03$ & $0.0033 \& 0.01$ \\
$C_{\text {Tmed }}^{2} \& C_{\text {Tmean }}^{2}, 10^{-4} \mathrm{~K}^{2} \mathrm{~m}^{-2 / 3}$ & $0.18 \& 5.20$ & $0.11 \& 4.0$ & $0.08 \& 1.51$ & $0.11 \& 1.02$ & $0.12 \& 0.40$ & $0.15 \& 2.41$ \\
\hline
\end{tabular}

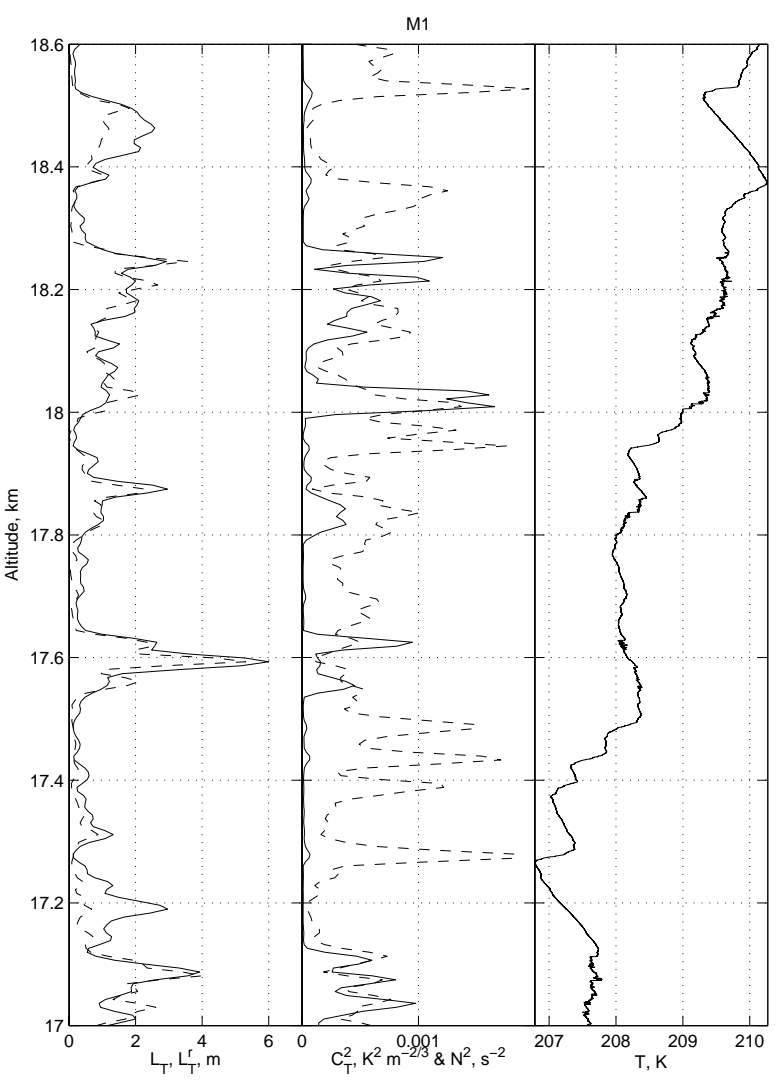

Fig. 4. Same as Fig. 3, but for flight M1 in the stratosphere.

the dynamic stability conditions around the maxima of $\varepsilon, K$ and $C_{T}^{2}$ will be given in a subsequent work.

\section{Discussion}

Figures 2-4 showed that directly measured $L_{T}$ and $L_{T}^{r}$ estimated from $C_{T}^{2}$ measurements using Eq. (13) agree well, especially within layers associated with large random temperature irregularities. This good agreement suggests that the proposed model, based on the hypothesis of homoge- neous inertial turbulence, despite its unreality, can constitute a good approximation, especially within such layers. Another model relating $\varepsilon$ to $C_{T}^{2}$ has been proposed in the literature (see Eq. (14)) from which another estimate $L_{T}^{e}$ can be deduced from Eq. (15). The top panel of Fig. 8 represents a comparison of $L_{T}^{e}$ with directly measured $L_{T}$ for M1 in the troposphere and stratosphere. One can see that the general trends of data points are different from the diagonals in Fig. 8. For small values, directly measured $L_{T}$ are generally larger than the indirect $L_{T}^{e}$ while this ratio is generally opposite for larger values of $L_{T}$ in Fig. 8. Thus, the agreement is worse than the one between directly measured $L_{T}$ with $L_{T}^{r}$, estimated using Eq. (13) in Fig. 2. The difference may reflect the difference in the power of $N$ in denominators of Eqs. (13) and (15): Smaller $L_{T}$ values generally correspond to larger $N^{2}$ values and vice versa. Due to the larger power of $N$ in the denominator of Eq. (15), one should expect $L_{T}^{e}>L_{T}^{r}$ at small $N$ and $L_{T}^{e}>L_{T}^{r}$ at large $N$ (cf. Figs. 2 and 8). Thus, estimations of $L_{T}$ from $C_{T}^{2}$ using Eq. (13) give results which are more consistent with directly measured values than the estimations from Eq. (15). It is worth noting however that for the most commonly encountered values of $L_{T}$ (in the range 0.3$3 \mathrm{~m}$ ), the results of both Eqs. (13) and (15) are of the same order.

Figures 5-7 show that the altitude ranges of enhanced local turbulence parameters are observed primarily between 8 and $12 \mathrm{~km}$ for all balloon flights. These ranges and intensities vary with observation days, in accordance with local distributions of temperature and winds. Multi-year systematic studies of $\varepsilon$ and $K$ with the MU radar in Shigaraki (Fukao et al., 1994; Kurosaki et al., 1996) indeed showed maxima of these turbulence parameters between 8 and $12 \mathrm{~km}$. Therefore, the presence of enhanced turbulence mixing in the tropopause region may likely be almost a permanent feature above Shigaraki. These turbulent layers may be produced by convective instabilities in the layers of $N^{2} \rightarrow 0$, which frequently exist below the tropopause. Other sources of turbulence near the tropopause may be produced by shear instabilities due to large vertical gradients of wind in the tropo-stratospheric jet streams (Joseph et al., 2003, 2004). 


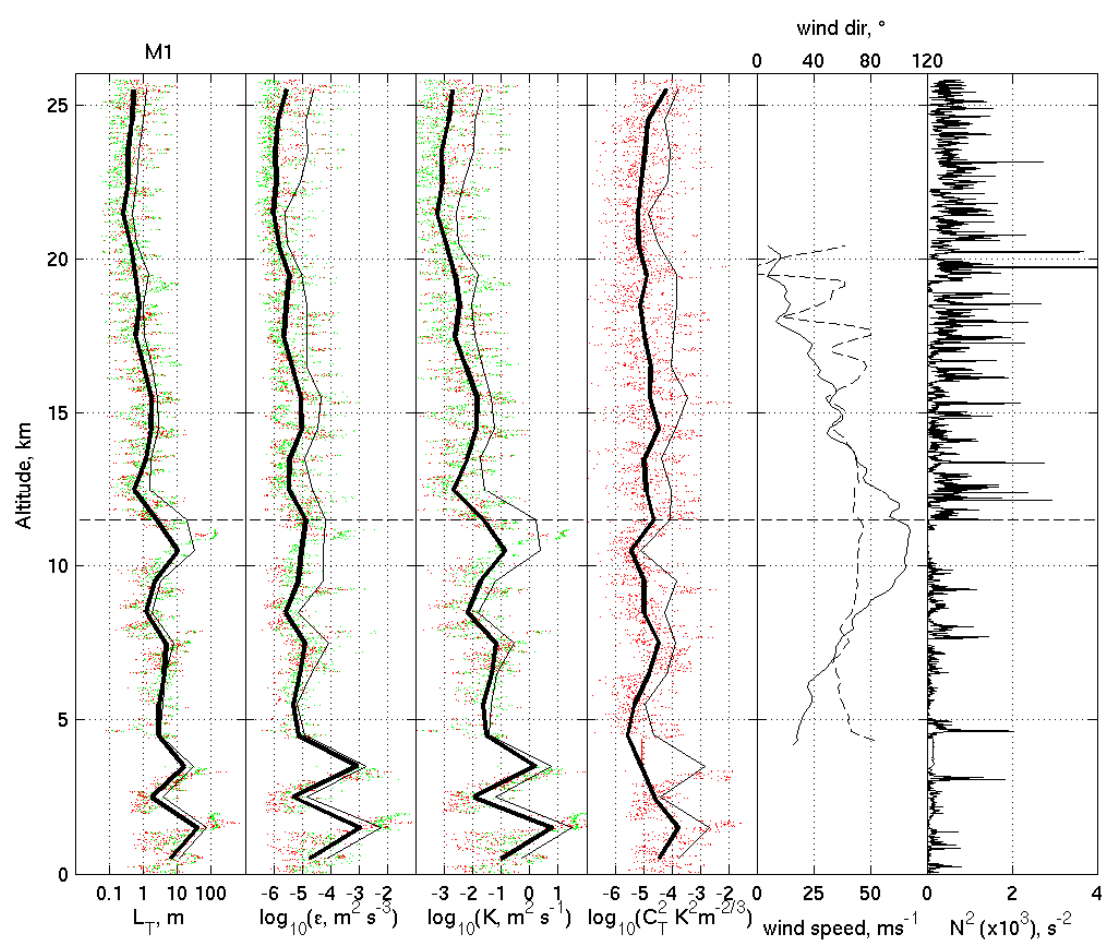

Fig. 5. Vertical distributions of turbulence parameters (from left to right): Thorpe length $L_{T}$, energy dissipation rate $\varepsilon$, diffusivity $K$, temperature structure constant $C_{T}^{2}$ with their median (thick solid lines) and mean (thin solid lines) values for segments of $1 \mathrm{~km}$ in thickness, wind speed (solid line) and direction (dashed line) and squared Brünt-Väisälä frequency $N^{2}$ for flight M1. Both directly measured and estimated values of $L_{T}, \varepsilon$, and $K$ are shown with green and red dots, respectively. The horizontal dashed line shows the temperature gradient tropopause height.

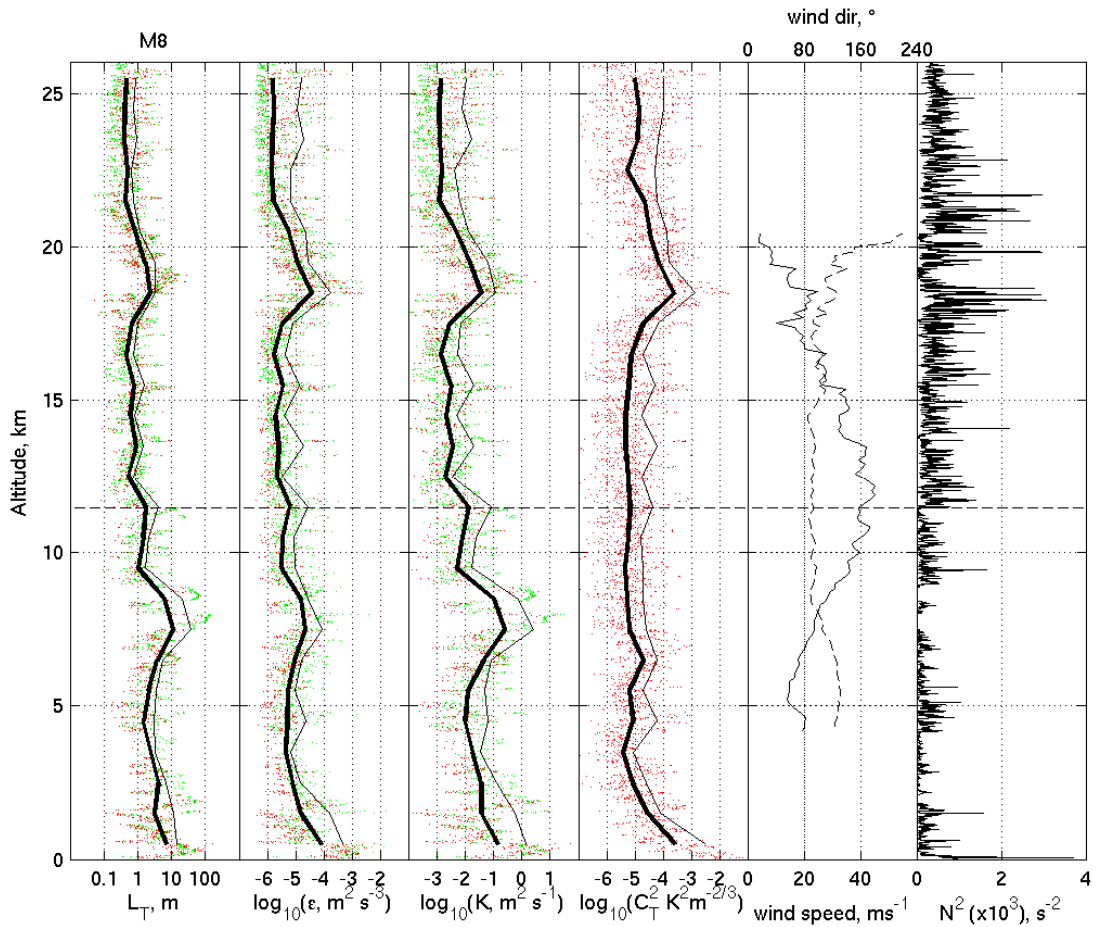

Fig. 6. Same as Fig. 5, but for flight M8. 


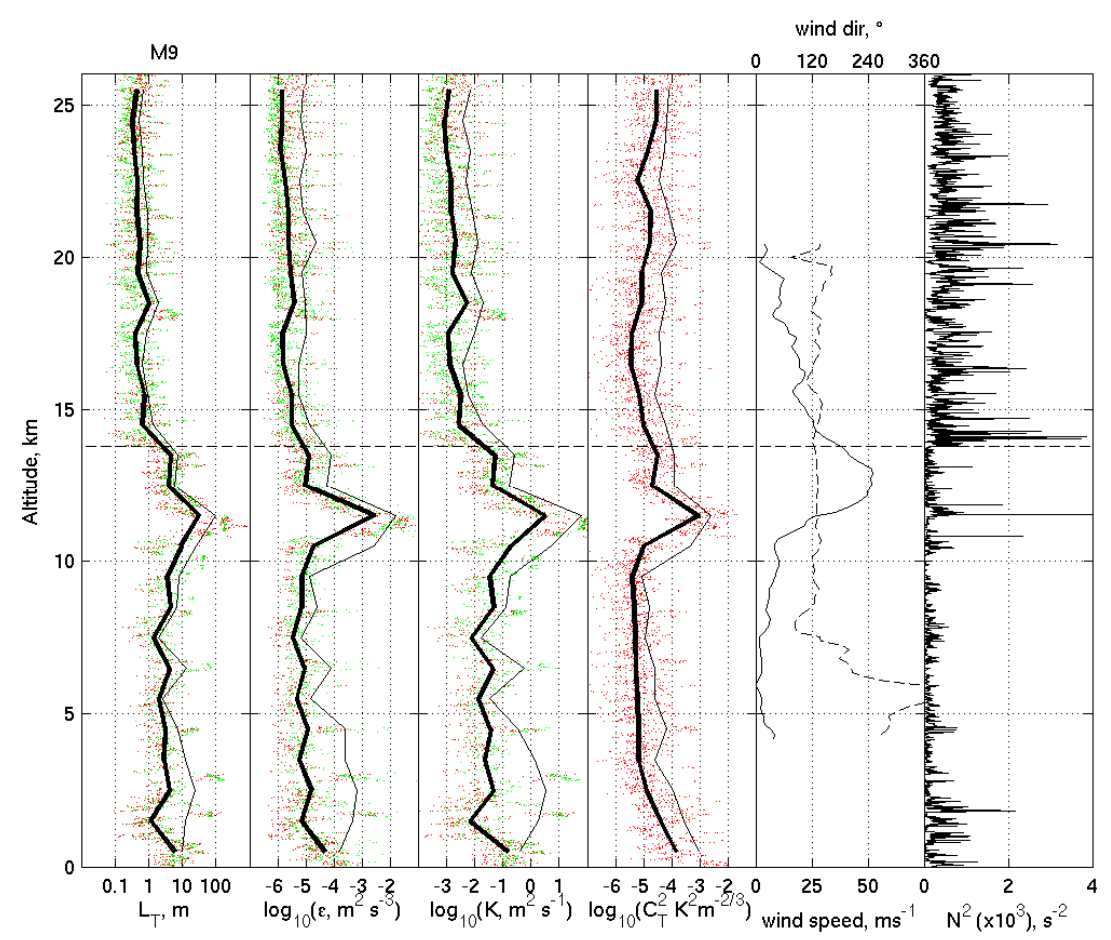

Fig. 7. Same as Fig. 5, but for flight M9.

The layers of turbulence maxima at altitudes 10-12 observed for flights M1 and M9 in Figs. 5 and 7 illustrate the different kinds of instabilities in the atmosphere. In the flight M1 the maxima of measured and reconstructed Thorpe lengths at altitudes $10-12 \mathrm{~km}$ are located within a broad layer of small convective stability with average $N^{2} \approx 2.610^{-5} \mathrm{~s}^{-2}$. In the strong turbulent layer observed at these heights for flight M9, the mean static stability was $N^{2} \sim 1.710^{-4} \mathrm{~s}^{-2}$ with larger local maxima (Fig. 7), but a large vertical gradient of horizontal wind of $\left|\partial u_{0} / \partial z\right|$ exceeding $35 \mathrm{~ms}^{-1} \mathrm{~km}^{-1}$ which can be deduced from wind, exists in the lower part of the tropo-stratospheric jet stream.

A comparison of all turbulence parameters in the mentioned layers for M1 and M9 in Figs. 5 and 7 reveals some differences caused by the differences in the mechanisms of their excitation. In the possible convectively unstable turbulent layer observed during the flight M1 a large maximum of Thorpe length is associated with the maxima of $\varepsilon$ and $K$ and with the minimum of $C_{T}^{2}$. This may indicate that in a convectively unstable layer, the Thorpe length reflects the thickness of the layer rather than the actual displacements of fluid particles; also, a small amount of turbulence energy here is enough to produce substantial vertical displacements of fluid parcels. But according to Eq. (7), these large vertical displacements are not associated with strong temperature fluctuations, as far as $N^{2} \sim 0$ in this layer. Relatively small turbulent energy and potential temperature gradients inside the unstable region may also suppress the processes of heat diffusion there (but not constituent diffusion). In a more convectively stable turbulent layer at altitudes of $10-12 \mathrm{~km}$ during the flight M9 in Fig. 7 all turbulent characteristics have strong maxima. In the case of $N^{2}>0$, large vertical displacements of fluid parcels require substantial turbulent energy and produce large temperature fluctuations and turbulent diffusivities.

For the flight M8 (Fig. 6), substantial maxima of turbulence parameters were observed around $18-20 \mathrm{~km}$. Maxima are also observed above the tropopause in the other profiles but they are not so strong. Statistical analysis of $\varepsilon$ and $K$ with the MU radar (Fukao et al., 1994; Kurosa et al., 1996) also reveals some local maxima at altitudes $16-20 \mathrm{~km}$. The turbulent altitude range around $18-20 \mathrm{~km}$ in M8 occurs in the convectively stable layer, possibly with a significant vertical shear of horizontal wind. This case would be similar to the case observed in M9 around $10-12 \mathrm{~km}$.

Figures 5-7 show that the horizontal wind speed above the altitude $15 \mathrm{~km}$ is generally smaller than that in the tropostratospheric jet stream and reveals frequent wave-like structures which are more pronounced in the stratosphere, especially for flight M1. They may be produced by gravity waves propagating from the troposphere or may be generated by geostrophic adjustment near the jet stream, for example. Local increases in the wave sources and their amplitudes may produce substantial wind shears capable of making turbulent layers. One of the reasons for an increase in the amplitudes of atmospheric waves propagating from the troposphere and in turbulence generation could be the sharp increase in $N^{2}$ in the tropopause region (VanZandt and Fritts, 1989; Gavrilov and Fukao, 2004).

Frequent observations of strong turbulent diffusivities near and above the tropopause (see Figs. 5-7 and discussion 
above) are very important for a further understanding of processes of transport of natural and anthropogenetic atmospheric gas and aerosol species between the troposphere and stratosphere. For example, at present, the atmospheric "Brewer-Dobson" general circulation is assumed to be the most important mechanism for the stratospheric ozone transportation to the troposphere (Holton, 1986). The role of mesoscale motions and turbulence in global ozone transport is unclear (Lamarque and Hess, 2003). The combined effect of the "Brewer-Dobson" circulation and quasi-horizontal mixing by large-scale eddies is equivalent to $K \sim 0.2 \mathrm{~m}^{2} \mathrm{~s}^{-1}$ in the tropopause region (Holton, 1986). Distributions of Figs. 5-7 show that the local $K$ near and above $10 \mathrm{~km}$ may be frequently much larger (up to $K \sim 10^{0}-10^{2} \mathrm{~m}^{2} \mathrm{~s}^{-1}$ ). Large local values of $K$ in the tropopause region were also measured using radar techniques, for example, by Fukao et al. (1994), Kurosaki et al. (1996), Pavelin et al. (2002), Whiteway et al. (2003), etc.

Such strong local turbulent diffusivities may produce substantial local turbulent fluxes of ozone, and other gas and aerosol species. Distributions of $K$ in Figs. 5-7 show that turbulence is very intermittent and $K$ is very variable in the tropo-stratosphere. This may produce substantial variability of local turbulent fluxes of atmospheric species (see Gavrilov et al., 2004 for turbulent ozone fluxes). There is a problem of estimation of the contribution of these local fluxes produced by intermittent turbulence into the mean transport of admixtures. There are doubts whether the median and average values of $K$ given in Table 2 correctly represent effective mixing by intermittent turbulence. A number of approaches were developped to account for random and wave intermittency of turbulent diffusion (see review by Fritts and Alexander, 2003). Dewan (1981) and Woodman and Rastogi (1984) suggested that the random occurrence of turbulent layers may produce a random process of intermittent diffusion and an effective turbulent diffusivity of this ensemble should be introduced. Fritts and Dunkerton (1985) and Gavrilov and Yudin (1992) showed that the intermittency of turbulence generated by gravity waves may lead to the difference in diffusivity of momentum and heat thus making an increase in the effective Prandtl number. Stokes diffusion may also contribute to atmospheric mixing (Hocking, 1999).

\section{Conclusions}

In the present paper, turbulence parameters in the tropostratosphere have been estimated using high-resolution balloon temperature measurements from the MUTSI campaign. Vertical profiles of the specific dissipation rate of turbulent kinetic energy, $\varepsilon$, and turbulent diffusivity, $K$, are estimated from Thorpe lengthscale, $L_{T}$. The last may be directly measured by the sorting of potential temperature profiles or estimated from measured temperature structure constant, $C_{T}^{2}$, using Eq. (13), assuming adiabatic vertical displacements or Eq. (15), based on turbulent energy balance consideration. Both values show satisfactory agreement and may be used
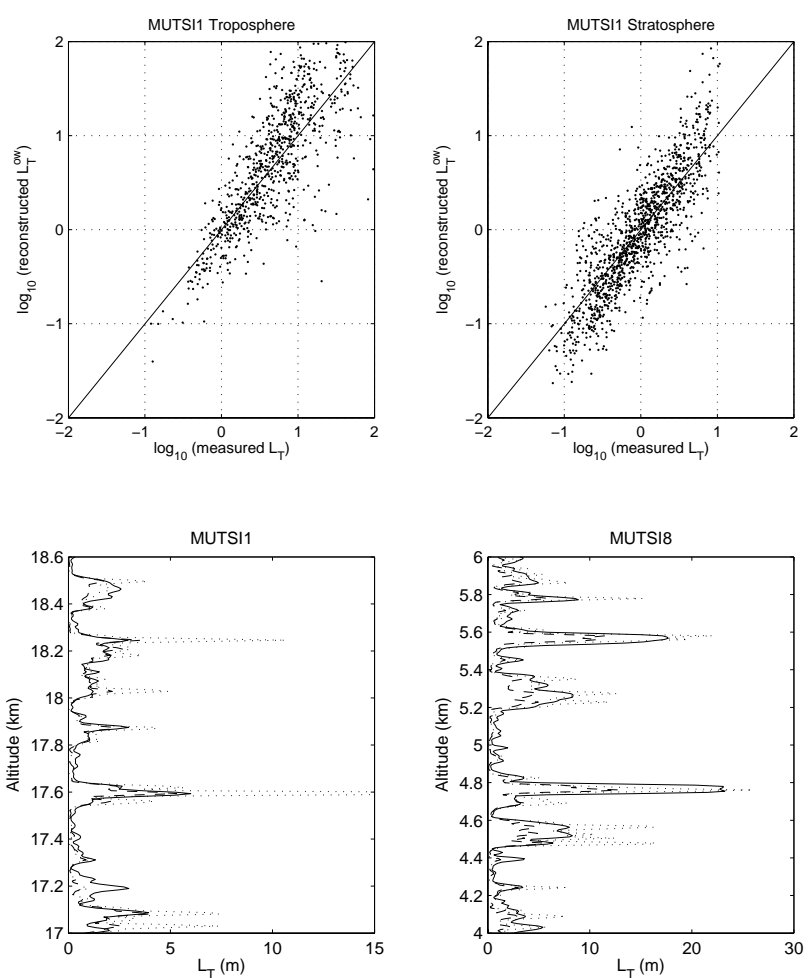

Fig. 8. Thorpe lengths directly measured and reconstructed with Eq. (15) (top left) for flight M1, for the troposphere (left) and stratosphere (top right), also directly measured (solid lines), reconstructed with Eq. (13) (dashes) and reconstructed with Eq. (15) (dots) for the same ranges as in Fig. 3 (bottom left) and Fig. 4 (bottom right).

for estimating turbulent characteristics. Estimations show that Eq. (13) gives estimations of the Thorpe length that are more consistent with direct measurements, than the estimations given by Eq. (15).

Vertical profiles of analyzed turbulence characteristics show substantial intermittency of turbulence, giving large dispersion of their local, median and average values. General trends correspond to a decrease in $\varepsilon$ and $K$ from the boundary layer up to altitudes $20-25 \mathrm{~km}$. Layers of increased turbulence are systematically observed in the tropo-stratosphere, which may be produced by instabilities of temperature and wind profiles mostly associated with gravity wave propagation. These maxima may substantially increase local values of turbulence characteristics, which may influence diffusion and mixing of atmospheric gas species in the tropostratosphere. Existence of substantial local turbulent diffusivities in Fig. 8 makes solving the problem of estimating effective diffusion by intermittent turbulence more important and requires further balloon, MST radar and other observations of turbulence in the tropo-stratosphere. In a subsequent paper, we are planning to compare the present estimations of turbulence parameters with those provided simultaneously by MU radar. 
Acknowledgements. The authors wish to thank very much W. Smyth and the second referee for their useful comments. These studies were partly supported by the Russian Basic Research Foundation.

Topical Editor F. D'Andrea thanks two referees for their help in evaluating this paper.

\section{References}

Agrovskii, B. S. and Kukharets, V. P.: Laser-Acoustic Measurements of Turbulent Humidity Fluxes: Preliminary Results, Atmospheric and Oceanic Physics, Izvestia Russian Acad. Sci., 34, 209-214, 1998.

Alisse, J. R.: Turbulence en atmosphère stable. Une étude quantitative, Thèse de doctorat. Univ. Paris VI, 1999.

Bertin, F., Barat, J., and Wilson, R.: Energy dissipation rates, eddy diffusivity, and the Prandtl number: an in-situ experimental approach and its consequences on radar estimates of turbulent parameters, Radio Sci., 32, 791-804, 1997.

Bertin, F., Van Velthoven, P. F. J., Bessemoulin, P., Ney, R., and Massebeuf, M.: Wave-turbulence interactions observed in the lower stratosphere by the PROUST UHF radar and GPS radiosoundings, J. Atmos. Solar-Terr. Phys., 61, 663-673, 1999.

Caldwell, D. R.: Oceanic turbulence: big bangs or continuous creation?, J. Geophys. Res., 88, 7543-7550, 1983.

Cho, J., Newell, Y. N., Anderson, R. E., Barrick, B. E., Thornhill, J. D., and Lee, K.: Characterizations of tropospheric turbulence and stability layers from aircraft observations, J. Geophys. Res., 108(D20), 8784, doi:10.1029/2002JD002820, 2003.

Dewan, E. M.: Turbulent vertical transport due to thin intermittent mixing layers in the atmosphere and other stable fluids, Science, 211, 1041-1042, 1981.

Dillon, T. M.: Vertical overturns: a comparison of Thorpe and Ozmidov length scales, J. Geophys. Res., 87, 9610-9613, 1982.

Dillon, T. M. and Park, M. M.: The available potential energy of overturns as an indicator of mixing in the seasonal thermocline, J. Geophys. Res., 92, 5345, 1987.

Dole, J. and Wilson, R.: Turbulence dissipation rates and vertical diffusivity in the stratosphere from radar observations, Physics and Chemistry of the Earth, Part B, 26, 225-229, 2001.

Fer, I., Skogseth, R., and Haugan, P. M.: Mixing of the Storjorden overflow (Svalbard Archipelago) inferred from density overturns, J. Geophys. Res., 109(C01005), 1-14, 2004.

Ferron, B., Mercier H., Speer K., Gargett A., and Polzin K.: Mixing in the Romanche Fracture zone, J. Physic. Ocean., 28, 19291945, 1998.

Fritts, D. C. and Alexander, M. J.: Gravity wave dynamics and effects in the middle atmosphere, Rev. Geophys. 41, 1, doi:10.1029/2001RG000106.

Fritts, D. C. and Dunkerton, T. J.: Fluxes of heat and constituents due to convectively unstable gravity waves, J. Atmos. Sci., 42, 549-556, 1985.

Fukao, S., Yamanaka, M. D., Ao, N., Hocking, W. K., Sato, T., Yamamoto, M., Nakamura, T., Tsuda, T., and Kato, S.: Seasonal variability of vertical eddy diffusivity in the middle atmosphere, 1. Tree-year observations by the middle and upper atmosphere radar, J. Geophys. Res., 99, 18 973-18 987, 1994.

Furumoto, J. and Tsuda, T.: Characteristics of energy dissipation rate and effect of humidity on turbulence echo power revealed by MU radar-RASS Measurements, J. Atmos. Solar-Terr. Phys., 63, 285-294, 2001.
Galbraith, P. S. and Kelley, D. E.: Identifying overturns in CTD profiles, J. Atm. Ocean. Tech., 13, 688-702, 1996.

Gargett, A. E.: Velcro measurement of turbulent kinetic energy dissipation rate $\varepsilon$, J. Atmos. Oceanic Tech., 16, 1973-1993, 1999.

Gavrilov, N. M., Richmond, A. D., Bertin, F., and Lafeuille, M.: Investigation of seasonal and interannual variations of internal gravity wave intensity in the thermosphere over Saint Santin, J. Geophys. Res., 99, 6297-6306, 1994.

Gavrilov, N. M. and Fukao, S.: Numerical and the MU radar estimations of gravity wave enhancement and turbulent ozone fluxes near the tropopause, Ann. Geophys., 22, 3889-3898, 2004,

\section{SRef-ID: 1432-0576/ag/2004-22-3889.}

Gavrilov, N. M., Fukao, S., Hashiguchi, H., Kita, K., Sato, K., Tomikawa, Y., and Fujiwara, M.: Study of Atmospheric Ozone and Turbulence From Combined MU Radar and Ozonesonde Measurements in Shigaraki, Japan., Proc. XX Quadrennial Ozone Symp., Kos, Greece, 1-8 June 2004, 1, 41-42, 2004.

Gavrilov, N. M. and Yudin, V.A.: Model for Coefficients of Turbulence and Effective Prandtl Number Produced by Breaking Gravity Waves in the upper Atmosphere, J. Geophys. Res., 97, 76197624, 1992.

Gibson, C. H.: On the scaling of vertical temperature gradient spectra, J. Geophys. Res., 87, 8031-8038, 1982.

Gurvich, A. S., Kan, V.,. Savchenko, S. A, Pakhomov, A. I., Borovikhin, P. A., Volkov, O. N., Kaleri, A., Yu., Avdeev, S. V., Korzun, V. G., Padalka, G. I., and Podvyaznyi, Ya. P.: Studying the turbulence and internal waves in the stratosphere from spacecraft observations of stellar scintillation: I. Experimental technique and analysis of the scintillation variance, Izvestiya, Atmospheric and Oceanic Physics, Izvestia Russian Acad Sci., 37, 436-451, 2001.

Hall, C. M., Meek, C. E., and Manson, A. H.: Turbulent energy dissipation rates from the University of Tromso/University of Saskatchewan MF radar, J. Atmos. Solar-Terr. Phys., 60, 437440, 1998.

Hecht, J. H., Liu, A. Z., Bishop, R. L. Clemmons, J. H., Gardner, C. S., Larsen, M. F., Roble, R. G., Swenson, G. R., and Walterscheid, R. L.: An overview of observations of unstable layers during the Turbulent Oxygen Mixing Experiment (TOMEX), J. Geophys. Res., 109, D02S01, 2004.

Hocking, W. K.: The Dynamical Parameters of Turbulence Theory as they apply to Middle Atmosphere Studies", Earth, Planets and Space, 51, 525-541, 1999.

Hocking, W. K. and Mu, K. L.: Upper and Middle Tropospheric Kinetic Energy Dissipation Rates from Measurements of Cn2 - Review of Theories, in-situ Investigations, and Experimental Studies using the Buckland Park Atmospheric Radar in Australia, J. Atmos. Terr. Phys., 59, 1779-1803, 1997.

Holton, J. R.: A dynamically based transport parameterization for one-dimensional photochemical models of the stratosphere, J. Geophys. Res., D91, 2681-2686, 1986.

Joseph, B., Mahalov, A., Nikolaenko, B., and Tse, K. L.: High resolution DNS of jet stream generated tropopausal turbulence, Geophys. Res. Lett., 30, 1525, doi:10.1029/2003GL017252, 2003.

Joseph, B., Mahalov, A., Nikolaenko, B., and Tse, K.L.: Variability of turbulence and its outer scales in a model tropopause jet, J. Atmos. Sci., 61, 621-643, 2004.

Kao, C.-Y. J., Cooper, D. I., Reisner, J. M., Eichinger, W. E., and Ghil, M.: Probing near-surface atmospheric turbulence with high-resolution lidar measurements and models, J. Geophys. Res., 108, doi:10.1029/2001JD000746, 2002. 
Kelley, M. C., Kruschwitz, C. A., Gardner, C. S., Drummond, J. D., and Kane, T. J.: Mesospheric turbulence measurements from persistent Leonid meteor train observations, J. Geophys. Res., 108(D8), doi:10.1029/2002JD002392, 2003.

Kolmogorov, A. N.: A refinement of previous hypotheses concerning the local structure of turbulence in a viscous incompressible fluid at high Reynolds number, J. Fluid. Mech., 13, 82-85, 1962.

Khananian, A. A.: Some results of investigating small-scale turbulence of middle atmosphere with artificial luminous and smoke clouds, Advances in Space Research, 17, 49-52, 1996.

Kurosaki, S., Yamanaka, M. D., Hashiguchi, H., Sato, T., and Fukao, S.: Vertical eddy diffusivity in the lower and middle atmosphere: a climatology based on the MU radar observations during 1986-1992, J. Atmos. Terr. Phys., 58, 727-734, 1996.

Lamarque J. F. and Hess P.: Stratosphere-troposphere exchange: Local processes, Enciclopedia of Atmospheric Sciences, edited by: Holton, J. R., Academic Press, Amsterdam-New YorkTokyo, 2143-2150, 2003.

Lilly, D. K., Waco, D. E., and Adelfang, S. I.: Stratospheric mixing estimates from high-altitude turbulence measurements, J. Appl. Meteorol., 13, 488-493, 1974.

Lübken, F. J.: Seasonal variation of turbulent energy dissipation rates at high latitudes as determined by in-situ measurements of neutral density fluctuations, J. Geophys. Res. 102(D12), 13,44113,456, 1997.

Lübken, F. J., Rapp, M., and Hoffmann, P.: Neutral air turbulence and temperatures in the vicinity of polar mesosphere summer echoes, J. Geophys. Res., 107, doi:10.1029/2001JD000915, 2002.

Luce, H., Crochet, M., Dalaudier, F., and Sidi, C.: An improved interpretation of VHF oblique radar echoes by a direct balloon $\mathrm{Cn} 2$ estimation using a horizontal pair of sensors, Radio Sci., 32, 1261-1268, 1997.

Luce, H., Fukao, S., Yamamoto, M., Sidi, C., and Dalaudier, F.: Validation of winds measured by MU radar with GPS radiosondes during the MUTSI campaign, J. Atmos. Ocean Technol., 18, 817-829, 2001

Luce, H., Fukao, S., Dalaudier, F., and Crochet, M.: Strong mixing events observed near the tropopause with the MU radar and highresolution balloon techniques, J. Atmos. Sci., 59, 2885-2896, 2002.

Moum, J. N.: Energy-containing scales of turbulence in the ocean thermocline, J. Geophys. Res., 101(C6), 14 095, 1996.

Naström, G. D. and Eaton, F. D.: Turbulence eddy dissipation rates from radar observations at $5-20 \mathrm{~km}$ at White Sands Missile Range, New Mexico, J. Geophys. Res., 102(D16), 19495 19506, 1997.

Ottersten, H.: Atmospheric structure and radar backscattering in clear air, Radio Sci., 4, 1179-1193, 1969.

Ozmidov, R. V.: On the turbulent exchange in a stably stratified ocean, Atmos., Ocean., Phys., 1965.
Pavelin, E., Whiteway, J. A., and Vaughan, G.: Observation of gravity wave generation and breaking in the lowermost stratosphere, J. Geophys. Res., 106, 5173-5179, 2001.

Pavelin, E., Whiteway, J., Busen, R., and Hacker, J.: Airborne observations of turbulence, mixing and gravity waves in the tropopause region: J. Geophys. Res., 107(D10), 4084, doi:10.1029/2001JD000775, 2002.

Roper, R. G.: Rocket vapor trail releases revisited: Turbulence and the scale of gravity waves: Implications for the imaging Doppler interferometry/incoherent scatter radar controversy, J. Geophys. Res., 101(D3), 7013-7018, 1996.

Satheesan, K. and Krishna Murthy, B. V.: Turbulence parameters in the tropical troposphere and lower stratosphere, J. Geophys. Res., 108, doi:10.1029/2000JD000146, 2002.

Smyth W.D., and Moum J.N., Length scales of turbulence in stably stratified mixing layers, Phys. Fluids, 12, 1327-1342, 2000.

Smyth, W. D., Moum, J. N., and Caldwell, D. R.: The Efficiency of Mixing in Turbulent Patches: Inferences from Direct Simulations and Microstructure Observations. J. Phys. Oceanogr., 31, 19691992, 2001.

Strunin, M. A. and Shmetern, S. M.: Evaluation of the Turbulent Mixing Coefficient in the Atmosphere from Airborne Measurements, Atmospheric and Oceanic Physics, Izvestia Russian Acad. Sci., 32, 29-35, 1996.

Tatarskii, V. I.: The effects of the turbulent atmosphere on wave propagation. Keter, 472, 1971

Thorpe, S. A.: Turbulence and mixing in a Scottish loch. Phil Trans. Roy. Soc. London, 286A, 125-181, 1977.

VanZandt, T. E. and Fritts, D. C.: A theory of enhanced saturation of the gravity wave spectrum due to increases in atmospheric stability. Pure Appl. Geophys., 130(2-3), 399-420, 1989.

Weinstock, J.: Energy dissipation rates of turbulence in the stable free atmosphere, J. Atmos. Sci., 38, 880-883,1981.

Wilson, R.: Turbulent diffusivity in the free atmosphere inferred by MST radar measurements: a review, Ann. Geophys., 22, 38693887, 2004,

SRef-ID: 1432-0576/ag/2004-22-3869.

Whiteway, J. A., Pavelin, E. G., Busen, R., Hacker, J., and Vosper, S.: Airborn measurements of gravity wave breaking at the tropopause, Geophys. Res. Lett., 30, doi:10.1029/2003GL018207, 2003.

Woodman, R. F. and Rastogi, P.K.: Evaluation of effective eddy diffusive coefficients using radar observations of turbulence in the stratosphere, Geophys. Res. Lett., 11, 243-246, 1984.

Zink, F., Vincent, R. A., Murphy, E., and Cote, O.: Comparison of radar and in-situ measurements of atmospheric turbulence, J. Geophys. Res., 109(D11), D11108, doi:10.1029/2003JD003991, 2004. 